\title{
Effects on brain activity after creative mathematical reasoning when considering individual differences in cognitive ability
}

Linnea Karlsson Wirebring ${ }^{\text {a, b }}$, Carola Wiklund-Hörnqvist ${ }^{\text {a, b }}$, Sara Stillesjö ${ }^{\text {b, e }}$, Carina Granberg $^{\text {d,e }}$, Johan Lithner ${ }^{\text {c, d }}$, Micael Andersson ${ }^{\text {b, f }}$, Lars Nyberg ${ }^{\text {b, f, g }}$ \& Bert Jonsson ${ }^{\text {b, e }}$

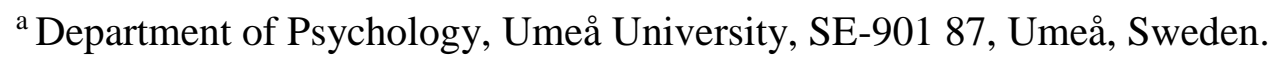

${ }^{\mathrm{b}}$ Umeå Center for Functional Brain Imaging (UFBI), Umeå University, SE-901 87, Umeå, Sweden

${ }^{c}$ Department of Science and Mathematics Education, Umeå University, SE-901 87, Umeå, Sweden

${ }^{\mathrm{d}}$ Umeå Mathematics Education Research Centre, Umeå University, SE-901 87, Umeå, Sweden e Department of Applied Educational Science, Umeå University, SE-901 87, Umeå, Sweden

${ }^{\mathrm{f}}$ Department of Integrative Medical Biology, Umeå University, SE-901 87, Umeå, Sweden

g Department of Radiation Sciences, Umeå University, SE-901 87, Umeå, Sweden

E-mail addresses to each author:

Linnea Karlsson Wirebring: linnea.karlsson@umu.se

Carola Wiklund-Hörnqvist: carola.wiklund-hornqvist@umu.se

Sara Stillesjö: sara.stillesjo@umu.se

Carina Granberg: carina.granberg@umu.se

Johan Lithner: johan.lithner@umu.se

Micael Andersson: micael.andersson@umu.se

Lars Nyberg: lars.nyberg@umu.se

Bert Jonsson: bert.jonsson@umu.se

\section{Corresponding author}

Correspondence concerning this article should be addressed to Linnea Karlsson Wirebring, Department of Psychology, Umeå University, SE-901 87 Umeå, Sweden. E-mail: linnea.karlsson@umu.se. 


\begin{abstract}
Many learning opportunities of mathematical reasoning in school encourage passive imitative learning procedures (algorithmic reasoning, AR) instead of engaging in more active constructive reasoning processes (e.g., creative mathematical reasoning, CMR). In the present study, we employed a within-subject mathematical intervention in the classroom with pupils in upper secondary schools followed by a test situation during brain imaging with fMRI one week later. We hypothesized that learning mathematical reasoning with the active (CMR) compared to the passive mode (AR) should lead to a CMR-effect, characterized by better performance and higher activity in brain regions related to semantic memory processing one week after learning. Despite controlling for individual differences in cognitive abilities, higher brain activity in key semantic brain regions such as left AG and left IFG was observed on tasks previously learnt with CMR compared to AR. Thus, encouraging pupils to engage in more active constructive processes when learning mathematical reasoning might have beneficial effects on learning and memory.
\end{abstract}

Keywords: mathematical reasoning, fMRI, angular gyrus, intervention, educational neuroscience, individual differences

\title{
Highlights:
}

- Active compared to passive mathematical learning lead to better performance

- Higher activity in brain regions key for semantic processing was observed after active compared to passive mathematical learning

- The effects of active mathematical learning on performance and brain activity did not interact with cognitive ability 
Mathematics is a core subject in most countries' educational systems. Still, when it comes to how mathematics is being taught in school, and how tasks in mathematics textbooks are commonly constructed, arguably more could be done to promote active learning (Freeman et al., 2014). It has been observed that many learning opportunities within the subject of mathematics encourage rote-learning or imitative, algorithmic procedures based on simply obeying to suggested solution templates (Boesen et al., 2014; Hiebert, 2003; Jäder, Lithner, \& Sidenvall). As an example, Jäder et al. (2019) analyzed mathematical textbooks from 12 countries and concluded that nearly $80 \%$ of the tasks promoted imitating a provided algorithmic solution template rather than actively engaging the pupil in more constructive reasoning processes. But how could such active learning of mathematical reasoning be promoted, and would it have effects on learning and memory?

A way of characterizing a constructive form of mathematical reasoning for solving training tasks, and corresponding ways to design teaching and textbook tasks, has been suggested and developed within the Learning by Imitative and Creative Reasoning research program (LICR; Lithner, 2008; 2017). The main focus within the LICR-program is to challenge the dominant way of learning mathematics through imitative learning strategies, with tasks promoting creative mathematical reasoning (CMR-tasks; see e.g., Lithner, 2008; 2017). In contrast to tasks promoting imitating a provided algorithmic solution template, CMR-tasks are designed to favor active learning because a solution template is not given to the pupil as a part of the task. Instead, the pupils are forced to novel mathematically based reasoning by actively engaging in constructing the solution method themselves. Empirical evidence have confirmed that CMR-tasks, compared to the more passive mode exemplified above: algorithmic reasoning (AR), have proven beneficial for mathematical learning (e.g., Jonsson, Granberg, \& Lithner, 2020a; Jonsson, Kulaksiz, \& Lithner, 2016; Jonsson, Norqvist, Liljekvist, \& Lithner, 2014; 
Norqvist, 2018; Norqvist, Jonsson, Lithner, Qwillbard, \& Holm, 2019; Wirebring, Lithner, et al., 2015).

Brain imaging support for a difference in how the brain is engaged during mathematical reasoning after initial training with CMR-tasks versus AR-tasks was obtained in a previous study (Wirebring, Lithner, et al., 2015). A fronto-parietal brain network was commonly engaged when participants solved mathematical test questions, which is consistent with other findings that the inferior frontal gyrus (IFG) and angular gyrus (AG) are recruited during advanced mathematics (Zhou et al., 2018). In addition, differences in recruitment of the left AG were observed as a function of learning method (AR > CMR). The left AG has repeatedly been implicated in studies of simple arithmetical learning (see e.g. Zamarian, Ischebeck, \& Delazer, 2009). Differential AG activity in the Wirebring, Lithner, et al. (2015) study was interpreted in relation to the notion that activity in this region is modulated by the demands on verbal retrieval strategies (Dehaene, Piazza, Pinel, \& Cohen, 2003). Higher activity in left AG has been observed for practiced compared to novel arithmetic problems (Delazer et al., 2003; Ischebeck et al., 2006). Left lateralized AG activity has been seen to mirror memory retrieval-based strategies rather than computational strategies in multiplication (Grabner et al., 2009) and increases in left AG activity has been observed as a function of learning multiplication problems (Ischebeck, Zamarian, Egger, Schocke, \& Delazer, 2007). Learning mathematics through CMR tasks is also expected to require retrieval effort in terms of forming an appropriate retrieval strategy (Kim, 2020), allocation of attention to memory (Cabeza, Ciaramelli, Olson, \& Moscovitch, 2008) as well as strengthening mathematical semantic knowledge related to terminologies and principles (Zhou et al., 2018). Seghier (2013) has proposed a unified framework for the multiple functions ascribed to the AG.

Interestingly, a relation between individual differences in cognitive abilities and brain activation in parietal and frontal cortices during mathematical processing has been 
observed (Grabner et al., 2007; Grabner, Reishofer, Koschutnig, \& Ebner, 2011; Gullick, Sprute, \& Temple, 2011; Price, Mazzocco, \& Ansari, 2013; Wirebring, Lithner, et al., 2015). For example, Grabner et al. (2007) identified a positive relation between mathematical and numerical IQ and signal change in AG during arithmetic problem solving. Thus, the way the brain is activated during mathematical reasoning might be modulated by individual differences in cognitive ability.

Here we present a large-scale study of brain activity during mathematical reasoning after initial CMR or AR training. Because an interaction between cognitive abilities and learning methods that require more cognitive effort (e.g., CMR) cannot be ruled out, we opted for a factorial design (mathematical learning method by cognitive ability). Based on the relevant evidence from previous studies, we hypothesized differential recruitment of the left AG region. A more open question was the direction of the effect. One possibility is that CMR should be more beneficial for learning than AR because the initial effort exerted during learning with CMR should strengthen semantic memory processing and representations over time. If so, we predicted that higher activity in left AG, as well as other regions related to controlled retrieval and selection of semantic knowledge such as IFG (Binder \& Desai, 2011; Martin \& Chao, 2001; Zhou et al., 2018) should be observed on tasks learned through CMR compared to AR. To the extent that individuals with relatively higher cognitive abilities are able to form even stronger semantic representations, and are more able to mobilize the appropriate semantic control network (Hoffman, 2018), individuals with higher cognitive ability were expected to recruit these regions (i.e., IFG and AG) to a higher degree than individuals with lower cognitive abilities.

\section{Materials and Methods}

\section{Participants}


The current study is part of a large data collection aimed at answering questions related to cognitive learning strategies (see also Jonsson et al., 2020a; Jonsson, WiklundHörnqvist, Stenlund, Andersson, \& Nyberg, 2020b; Wiklund-Hornqvist, Stillesjo, Andersson, Jonsson, \& Nyberg, 2021). At the outset, 324 pupils were recruited for the study from third year classes in local upper secondary schools and were enrolled in programs with a focus on the natural sciences, technology and economics. Out of these participants, a subsample of 72 participants (32 male; $M_{\mathrm{Age}}=18.0, S D=.41$ ) took part in the mathematical learning intervention (Day 1), volunteered for fMRI (Day 7), and met the inclusion criteria for fMRI, i.e., all participants were neurologically healthy, right-handed by self-report and had normal or corrected-to-normal vision. Data from one participant had to be discarded from the fMRI data analyses due to extensive head movements. All participants signed a written informed consent before participation. For participants who had not attained a legal age of majority (18 years; $n$ $=5$ ), written informed consent was obtained from the participant and both caregivers. The study was conducted in accordance with the Helsinki declaration and approved by the Regional Ethical Review Board in Umeå (ref number, 2016/259-31).

\section{Design, Procedure and Materials}

Prior to the learning intervention, all 324 participants were first tested with an extensive battery of cognitive ability measures (see Fig. 1a, and below for details). For the learning intervention, the study entailed a within-subject design where each participant learned to solve mathematical tasks in two learning conditions: AR and CMR (see Fig. 1a and Supplementary Fig. S1). At Day 1, participants learned to solve mathematical tasks in the classroom, and one week later, participants came back to be tested on the same tasks while undergoing fMRI (see Fig. 1b for the fMRI trial design).

\section{Cognitive Ability Measures}


In order to capture cognitive abilities in a broad sense, nine different cognitive ability measures were administered as computerized tests a few weeks prior to the learning intervention. These included measures of general fluid intelligence (Ravens APM: Raven, Raven, \& Court, 1998), working memory capacity (Operation span: Unsworth, Heitz, Schrock, \& Engle, 2005), episodic memory (Modified associative learning test: Lövdén, 2003), processing speed (Number- and letter comparison: Schmiedek, Lövdén \& Lindenberger, 2010), visuospatial short-term memory (Block span: Nyroos, Jonsson, Korhonen, \& Eklöf, 2015; Wiklund-Hörnqvist, Jonsson, Korhonen, Eklöf, \& Nyroos, 2016), verbal short-term memory (Digit span: Nyroos et al., 2015; Wiklund-Hörnqvist et al., 2016) and updating (Letter running span: Dahlin, Neely, Larsson, Backman, \& Nyberg, 2008; Keep track: Miyake et al., 2000). For a description of the specifics of each of these tasks, and the implementation and procedure, see Jonsson et al. (2020b).

To be able to relate individual differences in cognitive ability, in a broad sense, to the effects of the mathematical learning intervention on later performance and brain activity, we relied on a composite score based on performance on the cognitive ability measures mentioned above. This composite score was the factor score from a principal component analysis (PCA) run on the complete sample ( $N=324$; Jonsson et al., 2020b). The larger sample was divided into three equal groups based on each participant's value on the factor score, denoted low, intermediate and high cognitive ability groups. Importantly, each participant in the current fMRI study $(N=72)$ was categorized as low $(n=17)$, intermediate $(n=20)$ or high $(n=32)$ relative to the larger sample, making the categorization of participants in the current study less biased and more robust. In addition, a rationale for categorizing the participants in the current study into the three groups was to be able to relate to the study by Jonsson et al. (2020b) also theoretically. Jonsson and colleagues observed that the magnitude of the testing effect (the effect of another active learning method which compares vocabulary learning using 
retrieval practice with study) was independent of cognitive ability (low/intermediate/high), and we wanted to be able to investigate whether similar conclusions would follow when comparing CMR to AR (i.e. the CMR-effect). For details concerning distribution and intercorrelations of the cognitive tests, and details of the PCA, see Jonsson et al. 2020b.

\section{Mathematical Training}

Each participant was presented to 24 mathematical tasks in two learning conditions: the AR condition (12 tasks) and the CMR condition (12 tasks) (for task illustration, see Fig. 1a and Supplementary Fig. S1 and S2). Participants practiced individually in the classroom in front of a laptop, with school desks spaced apart. The matching of tasks with learning condition was counterbalanced, such that half of the participants were presented to the tasks the other way around (i.e., the 12 tasks used for the AR condition were used for CMR and vice versa). All participants started practicing in the AR condition, and after a short break continued with the CMR condition. The order was set like this in order to prevent carry-over effects from CMR to AR. This was motivated by the fact that most pupils should be acquainted with the elements of AR, because this is a common way of learning mathematics (e.g., Jäder et al., 2019), while CMR represents the more novel task design (Lithner, 2008; 2017). The set-up and the length of the intervention (e.g., the number of tasks to solve) was designed to be suitable as an in-class intervention and to avoid fatigue (the intervention lasted approximately 50 minutes $(\mathrm{AR})+$ short break +50 minutes $(\mathrm{CMR}))$.

The general design elements of the AR and CMR conditions have been described in detail in several of our previous papers (see e.g., Jonsson et al., 2020a; Jonsson et al., 2016; Jonsson et al., 2014; Lithner, 2017; Norqvist, 2018; Norqvist et al., 2019; Wirebring, Lithner, et al., 2015). The key difference between AR and CMR is that while the mathematical tasks in the AR condition provide a solution template, that is, a formula and an example, this part is completely left out in the CMR condition of the task. In the CMR condition, the participant is 
instead asked to create their own solution method and furthermore asked to construct the corresponding formula (see Fig. S1 and Fig. S2).

Each task consisted of several sub-tasks, where the layout was identical but where the exact numbers that should be calculated differed. The first sub-task in both conditions was always numerically easy, but the following sub-tasks asked for a numerical solution where it was important to have a solution method at hand, as the number grew too large to come up with a correct answer by for example imagining and counting the matches needed to construct 100 squares (see Fig. 1a; S1; S2). The third sub-task of each task in the CMR condition always asked the participant to construct their own solution formula (Fig. S1b). Independent of learning condition (CMR or AR), participants were given four minutes to learn the various sub-tasks of each task. If the pupils managed to solve all the sub-tasks, the software re-sampled sub-tasks until the 4 minutes had passed. Thus, an equal time-on-task for both learning conditions was ensured for all participants. After each answer given, participants received feedback on the correct answer. However, no correct answers were provided to tasks that asked the pupils to construct formulas (i.e., the third CMR task, the formula question; see Fig S1b). All participants had access to a small calculator on the side of the screen in order to even out differences in mental calculation skills as a hinder for learning and also to more closely mimic a real school situation.

\section{Mathematical Testing with fMRI}

One week after the mathematical learning intervention, the participants came to the fMRI scanner to undergo fMRI while solving randomly presented test instances of the 24 tasks they had previously trained on Day 1 (Fig. 1b). The test instances did not provide a formula or an example, and participants had to recreate the solution method themselves. Participants solved one test instance per task with 60 seconds at their disposal (see Fig. 1b). The exact numbers used in the test tasks were different from those used during training. Participants 
were instructed to push a button on a response pad when they had solved the task and, after a variable delay, they were shown four numerical response alternatives. Participants marked which of the alternatives was the correct one and, after a variable delay, moved on to the next task (Fig. 1b).

Upon completion of the fMRI protocol and the structural images, participants filled out a follow-up questionnaire outside the scanner. Participants were asked, for each of the 24 task sets, how difficult they thought it was, on a scale from 1 (very easy) to 7 (very difficult).

\section{fMRI Image acquisition}

Image acquisition was made on a 3T GE Discovery MR 750 scanner (General Electrics). Functional T2*-weighted images were obtained with a single-shot gradient echo EPI sequence used for blood oxygen level dependent imaging. The following parameters were used for the sequence: echo time: $30 \mathrm{~ms}$, repetition time: $2000 \mathrm{~ms}$ (37 slices acquired), flip angle: $90^{\circ}$, field of view: $25 \times 25 \mathrm{~cm}, 96$ × 96 matrix and $3.4 \mathrm{~mm}$ slice thickness. A 32 channel SENSE head coil was used. Signals arising from progressive saturation were eliminated through ten "dummy scans" performed prior to the image acquisition. The stimuli were presented on a computer screen that the participants viewed through a tilted mirror attached to the head coil. Presentation and reaction time data were handled by a PC running E-Prime 2.0 (Psychology Software Tools, Inc., USA) and fMRI optical response keypads (Current Designs, Inc., USA) were used to collect responses.

T1-weighted images were obtained with a 3D fast spoiled gradient echo sequence (FSPGR) in axial orientation. The following parameters were used: echo time: $3.2 \mathrm{~ms}$, repetition time: $8.2 \mathrm{~ms}$ (176 slices acquired), flip angle: $12^{\circ}$, field of view: 25 x $25 \mathrm{~cm}, 256$ x 256 matrix and $1 \mathrm{~mm}$ slice thickness.

\section{fMRI Data analyses}


The data was analyzed using SPM12 (Wellcome Department of Cognitive Neurology, UK) implemented in Matlab (R2014b) (Mathworks Inc., USA) and run through an inhouse program (DataZ). All images were corrected for slice timing, realigned to the first image volume in the series, and unwarped. Images were spatially normalized with Dartel (Ashburner, 2007). The individual T1 images were segmented, and a group specific mean template and individual flow fields were created with the DARTEL algorithm (Ashburner, 2007). The DARTEL template was used to normalize images to the anatomical space defined by the MNI atlas (SPM12), and smoothed using an $8.0 \mathrm{~mm}$ FWHM Gaussian filter kernel. Data were high-pass filtered with a cut-off of $128 \mathrm{~s}$.

The general linear model consisted of two effects of interest (tasks learnt in the AR condition and tasks learnt in the CMR condition, Fig. 1b) and six effects of no interest (AR ISI, AR alternative forced-choice, AR ITI, CMR ISI, CMR alternative forced-choice, CMR ITI). We chose to model the blocks associated with the two conditions as separate effects in order to incorporate potential differences during the ITI, alternative forced-choice and ISI that would not be of relevance to the core question addressed. The movement parameters were included as covariates of no interest. All regressors, except the movement regressors, were convolved with a hemodynamic response function. The time points when the mathematical task was shown were used as onset, and response times were used as duration.

In the first level analysis, model estimations were made for each participant. The individual model estimations were then taken into a second-level mixed model ANOVA with learning condition (AR/CMR) as within subject factor and cognitive ability group (low/intermediate/high) as between subject factor. With this analysis, it is possible to investigate whether there is a main effect of learning condition (AR/CMR) on the brain activity data acquired one week after learning. Moreover, it also enabled us to examine whether there 
is main effect of cognitive ability group and possible interactions between learning condition and cognitive ability group.

The statistical threshold was set to $p<.01$ (FDR-corrected) at the voxel level, and $k>15$ at the cluster level. The analysis was explicitly masked with a grey matter mask derived from a segmentation in SPM of the average of the individual MNI-normalized anatomical images of the participants in the study.

\section{Control Analyses}

For completeness, we related the composite score of cognitive abilities to performance and brain activity by including the score as a continuous variable. In terms of performance, we ran a regression analysis to investigate to what extent the cognitive composite score predicted the difference in performance between CMR and AR (the CMR-effect). In terms of brain activity, we added the cognitive composite score as a covariate of interest to a $t$-test between the conditions. Model estimations from each participant were taken into two secondlevel paired samples $t$-tests $(\mathrm{CMR}>\mathrm{AR}$ and $\mathrm{AR}>\mathrm{CMR}$, respectively) with the continuous composite score of cognitive abilities as a covariate of interest.

Moreover, we also controlled for differences in response times and performance in relation to the effect of $\mathrm{CMR} / \mathrm{AR}$. We added the difference in response times between the two conditions, and the difference in performance between the two conditions, respectively as covariates of no interest to two different $t$-tests between the conditions. Model estimations from each participant were taken into a second-level paired samples $t$-test (CMR > AR/AR > CMR) with the difference in response times or performance, respectively, as a covariate of no interest.

\section{Results}

\section{Behavioral Results}

\section{Test performance}


One week after learning, participants performed significantly better on test items that had been previously learned through CMR compared to AR (see Fig. $2 \mathrm{a}$ ): $M_{\mathrm{AR}}=.44, S D=$ .21 vs. $M_{\mathrm{CMR}}=.49, S D=.24, t(71)=-2.06, p=.04,95 \%$ CI [-.105, -.002]. In addition, significantly shorter response times were observed for test items learned through the CMR condition compared to AR: $M_{\mathrm{AR}}=40.9 \mathrm{~s}, S D=9.4 \mathrm{~s}$ vs. $M_{\mathrm{CMR}}=36.0 \mathrm{~s}, S D=8.8 \mathrm{~s} ; t(70)=6.44$, $p<.001,95 \%$ CI $[3.38,6.41]$. Comparing the subjective post-hoc difficulty ratings averaged over the 12 AR test items and the $12 \mathrm{CMR}$ test items, the difference was not significant: $M_{\mathrm{AR}}=$ $4.04, S D=.92$ vs. $M_{\mathrm{CMR}}=3.93, S D=.88 ; t(71)=1.18, p=.24,95 \%$ CI $[-.08, .30]$.

To investigate to what extent the benefits on later test performance after practicing with CMR compared to AR depends on cognitive ability, a $2 \times 3$ mixed model ANOVA was performed. Cognitive ability group (low, intermediate, high) was entered as a between-subjects factor and type of test item (i.e., from tasks that were learned through $\mathrm{AR}$ and CMR, respectively) as a within-subjects factor (Fig. 2b). This analysis yielded a non-significant main effect of condition (AR vs CMR: $F(1,66)=2.71, p=.10$ ) but a significant main effect of cognitive ability group (low/intermediate/high: $F(2,66)=24.8, p<.001, \eta_{\mathrm{p}}{ }^{2}=.43$ ). The higher cognitive ability, the better participants performed on the mathematical test independent of CMR/AR (see Fig. 2b). Post-hoc tests revealed significant differences in performance between all three cognitive ability groups (all $p$ 's $<.021$ ). There was however no significant interaction between cognitive ability group and condition $\left(F(2,66)=.76, p=.47, \eta_{\mathrm{p}}^{2}=.02\right)$.

For completeness, we ran a regression analysis to investigate to what extent the continuous cognitive composite score predicted the difference in performance between CMR and AR (performance CMR minus AR: the CMR-effect). The cognitive composite score did not significantly predict the CMR-effect, $\beta=.15, t(66)=1.28, p=.21$.

\section{Imaging Results}


Next, we turned to analyzing potential effects of learning condition (AR/CMR) and cognitive ability group on brain activation one week after learning. We observed significant main effects of condition (AR/CMR) on brain activity (see Fig. 3 and Table 1 for statistics), but no interaction between condition and cognitive ability group and no main effect of cognitive ability group at the predefined statistical threshold. Main effects of condition (AR/CMR) were mainly observed in a number of fronto-parietal clusters (see Fig. 3 and Table 1). As expected, higher activity in left IFG $[-40,46,10]$ and left AG $[-42,-60,48]$ was found when participants solved test items previously learned through CMR compared to AR (see Fig. 3a and 3b, and Table 1). In addition, significant main effects of condition were also seen in right mid PFC, posterior/middle cingulum, supramarginal gyrus and middle temporal cortex, where the latter two clusters were more activated for test items previously learned through AR compared to CMR (Figure 3b, Table 1). Because left AG and left IFG where regions of particular interest given our hypothesis, and for illustrative purposes, signal change in those regions was plotted as a function of cognitive ability group (see Fig. 3c). The same pattern was seen for all three cognitive ability groups, with a tendency for numerically less activation for the lower cognitive ability group compared to the others.

For completeness, entering the continuous cognitive composite score as a covariate to the $t$-test between the conditions (CMR vs AR and vice versa), did not affect the conclusions above. Left IFG/mid PFC, left AG, right mid PFC and posterior/middle cingulum were still more strongly activated when participants solved test items previously learned through CMR compared to AR. Importantly, no clusters covaried with the continuous cognitive composite score at the predefined statistical threshold. The effects observed between CMR and AR remained even when entering differences in performance and reaction time, respectively, as covariates.

\section{Discussion}


Here we hypothesized that constructing your own solutions to mathematical problems with creative mathematical reasoning (CMR-tasks; see e.g., Lithner, 2008; Lithner, 2017) should be more beneficial for learning than tasks promoting imitating a provided algorithmic solution template (AR-tasks) because the initial effort exerted during learning with CMR should have a beneficial effect on semantic memory processing and representation over time. We predicted differential involvement of key regions related to controlled retrieval and selection of semantic knowledge, such as left IFG and left AG (Binder \& Desai, 2011; Martin \& Chao, 2001; Seghier, 2013; Wirebring, Lithner, et al., 2015; Zhou et al., 2018) when comparing tasks learned through CMR compared to AR one week prior to scanning. We included individual differences in cognitive abilities as a factor and investigated whether higher cognitive abilities could be mirrored by stronger semantic representations and focused mobilization of the appropriate semantic control network (Grabner et al., 2007; Hoffman, 2018; Kim, 2020; Zhou et al., 2018). We also outlined whether cognitive abilities interacts with the effects of learning method.

With pupils participating in a within-subject intervention in the classroom, followed by a test situation during brain imaging with fMRI one week later, we observed better performance on test items learnt through CMR compared to AR. We thus replicate several previous studies, with a similar task design, in demonstrating a CMR-effect: that CMR-tasks are more effective in fostering mathematical learning than AR-tasks (see e.g., Jonsson et al., 2020a; Jonsson et al., 2016; Jonsson et al., 2014; Norqvist, 2018; Norqvist et al., 2019; Wirebring, Lithner, et al., 2015). Individuals with relatively higher cognitive abilities performed better than individuals with relatively lower cognitive abilities, one week after learning. Individual differences in cognitive abilities have been shown to predict academic achievement in various settings (Alloway \& Alloway, 2010; Gathercole, Pickering, Knight, \& Stegmann, 2004; Kyttälä \& Lehto, 2008; Wiklund-Hörnqvist et al., 2016) as well as performance on the 
type of tasks used in this particular study (Jonsson et al., 2020; Jonsson et al., 2014; Wirebring, Lithner, et al., 2015).

With brain imaging data, it becomes possible to observe neural evidence for differences in learning outcomes despite relatively small behavioral differences, especially in relation to the complexity of mathematical thinking (Sohn et al., 2004). In the present case, the brain imaging contrasts differ only in terms of previous training history (i.e. learning condition one week prior to the fMRI test session). We observed strong and reliable differences in brain activity in left IFG and left AG on tasks previously learned through CMR compared to AR. Left lateralized brain activity in especially IFG and AG is identified as key for semantic memory processing and conceptual representations (Binder \& Desai, 2011; Gray, Fry, \& Montaldi, 2020; Martin \& Chao, 2001) and is also repeatedly observed in relation to various forms of arithmetical and mathematical thinking (Dehaene et al., 2003; Wirebring, Lithner, et al., 2015; Zamarian et al., 2009; Zhou et al., 2018). Even though mathematical reasoning is likely to recruit brain regions unique to mathematical content (Amalric \& Dehaene, 2016, 2019) left AG has been found to be co-activated with lateral PFC regions, linked to semantic processing of the specific mathematical content (Amalric \& Dehaene, 2016). IFG has been suggested as part of a 'semantic working memory' system (Martin \& Chao, 2001), and evidence exists that higher activity in the left IFG is related to access of available semantic representations (Salami et al., 2010).

Parietal cortex has a well-documented role in representing memories. High activity in parietal cortex is a hallmark of retrieval success (Spaniol et al., 2009). Parietal cortex is likely a 'convergence zone' where modality specific information is bound together to form integrated semantic memories, in for example AG (Binder \& Desai, 2011; Binder, Desai, Graves, \& Conant, 2009; Bonner, Peelle, Cook, \& Grossman, 2013). A recent meta-analysis suggests that whereas the right AG is likely to code for perceptual features of a memory, the 
left AG supports retrieval of semantic and conceptual aspects of memory (Gray et al., 2020). Left AG is however a complex region with evidence that subregions of AG play different functional roles (Seghier, 2013). Activity in the more dorsal part of left AG that we observe here $(z=48)$ is likely to be linked with bottom-up processes during search from semantic memory (C. J. Price, 2010; Seghier, 2013) and automatic allocation of attention to memory (Cabeza et al., 2008; Ciaramelli, Grady, \& Moscovitch, 2008). Recent research suggests that one role of AG in arithmetical processing might be to mediate and control whether or not processes related to the task are employed by targeting relevant networks (Bloechle et al., 2016; Klein, Willmes, Bieck, Bloechle, \& Moeller, 2019). Specifically, Bloechle et al. (2016) and Klein et al. (2019) suggests that the left AG act as a 'circuit breaker' that adjusts and adapts relative attentional demands in the networks associated with magnitude manipulation and fact retrieval. Taken together, the pattern of brain activity observed in the present study suggests that learning with CMR might have beneficial effects on learning and memory by prompting semantic processing relevant to the task at hand.

Despite the robust performance differences between the cognitive ability groups, we observed a tendency that individuals with relatively higher cognitive abilities had higher brain activity in left IFG and left AG than individuals with relatively lower cognitive abilities (Fig. 3c), but importantly, there was no main effect of cognitive ability group on brain activation data. This is in contrast to a few previous studies that have identified a relation between individual differences in cognitive abilities and brain activation in parietal and frontal cortices during mathematical processing (Grabner et al., 2007; Grabner et al., 2011; Gullick et al., 2011; Price et al., 2013; Wirebring, Lithner, et al., 2015). For example, Grabner et al. (2007) found a positive relation between an individual's mathematical and numerical IQ and signal change in AG during arithmetic problem solving. A key feature distinguishing our study and some of the previous attempts is that here we focus on more advanced mathematical reasoning (see Fig. S2 
for examples of task details) instead of a direct relationship between cognitive abilities and basic arithmetical processing (Grabner et al., 2007; Grabner et al., 2011; Gullick et al., 2011; Price et al., 2013). Our results, together with the lack of interaction between cognitive ability group and learning condition, both concerning performance and brain activity, suggest that the three cognitive ability groups approach the CMR and AR test tasks with similar neurocognitive strategies. This resonates with previous studies that have failed to observe interactions on brain activity between numerical IQ and problem complexity (Grabner et al., 2007) even though intervention studies on mathematical learning methods, with ecologically valid didactical tasks, using fMRI at posttest are rare (e.g., Wirebring, Lithner, et al., 2015; see Foisy, Matejko, Ansari, and Masson 2020 for examples and a discussion). That even the lower cognitive ability group had significantly higher activity in left IFG and left AG on CMR tasks compared to AR tasks one week after learning can be taken as strong indication that all groups had the possibility to actively engage in semantic processing and form accessible representations. This opens up to the possibility that encouraging pupils to engage in more active constructive processes when learning mathematical reasoning might have beneficial effects on learning and memory for all, even when considering cognitive ability differences (Jonsson et al., 2020a, b). In order to even out performance differences between lower and higher ability pupils it might be important to boost cognitive processing in brain regions associated with semantic memory processing and conceptual representations among the lower ability pupils simply by extending the intervention. Hence, if there is a dose-response relationship between intervention and learning outcome, the lower cognitive ability group could have gained even more in terms of performance and brain activity if the intervention had been longer in duration. Research from related fields is promising in this respect. Donnelly, Huber, and Yeatman (2019) showed that for so-called "struggling" readers there was a clear dose-response relationship, with a linear increase in reading ability as a function of reading intervention intensity. 
The majority of brain imaging studies on mathematical cognition to date have focused on relatively simple arithmetical processing (for overviews see e.g. Arsalidou, PawliwLevac, Sadeghi, \& Pascual-Leone, 2018; Arsalidou \& Taylor, 2011; Dehaene et al., 2003; Peters \& De Smedt, 2018; Zamarian et al., 2009). Evidence in relation to how brain function and structure subserve the forms of more advanced or non-routine mathematics targeted here remains scarce (e.g., Wirebring, Lithner, et al., 2015; Zhou et al., 2018). The exact localization and direction of the left AG activation reported here differs from our previous study aiming to capture mathematical reasoning processes (Wirebring, Lithner, et al., 2015). This difference might be the result of a number of factors. For example, while Wirebring, Lithner, et al. (2015) had a between-subject design including only nine different task sets and an average of 23 minutes spent on the learning intervention, the present study had a within-subject design including 12 different task sets and 48 minutes training time per condition (resulting in 96 minutes in total and 24 task sets per participant). The difference with respect to time spent on the learning intervention is considerable. Moreover, the fMRI test session in the present study subjected each individual to 24 test items from the two different learning conditions which might have had a direct effect on left AG activation given the recent notion of AG as an attentional "circuit breaker" balancing retrieval (Bloechle, et al., 2019; Klein et al., 2019) and attentional (Cabeza et al., 2008) demands. Another important factor to consider is that the previous study included a cognitive-perceptual baseline task, where the task was to look at a similar display as the mathematical task display, albeit the task was to judge whether there was a spelling mistake (yes/no). Given the known importance of left AG for processes related to reading and comprehension (e.g. Price, 2010) subtracting this baseline activity from the mathematical task activity (Wirebring, Lithner, et al., 2015) might have canceled out memory related AG activity in unintended ways. 
Future research should consider designs allowing for multivariate pattern analysis of brain imaging data to create the possibility to detect more subtle activity differences after learning with CMR and AR in relation to individual differences in cognitive abilities (see e.g., Wirebring, Wiklund-Hornqvist, et al., 2015). Potentially, mental representations are less precise one week after learning AR comparing CMR. Moreover, targeting the learning phase is vital in order to investigate a gradual build-up of memory representations as a function of learning (e.g., Stillesjo, Nyberg, \& Wirebring, 2019). That would enable us to connect to the literature observing an important role for hippocampus for mathematical learning (e.g., Supekar et al., 2013). Our results suggest that mathematical learning should have a lot in common with concept learning.

\section{Conclusions}

In the present study we were able to demonstrate that active compared to more passive mathematical learning lead to better performance and increased brain activity one week after learning. We observed higher brain activity in regions key for semantic processing (left IFG and left $\mathrm{AG}$ ) after active constructive mathematical reasoning (CMR) compared to more passive imitative learning procedures (AR), and these effects did not interact with cognitive ability. We conclude that encouraging pupils to engage in more active constructive processes when learning mathematical reasoning might have beneficial effects on learning and memory as it supports semantic memory processing and representations.

\section{Declaration of competing interest}

Authors have no conflicts of interest to disclose.

\section{Acknowledgments}


This work was supported by the Swedish Research Council (grant number 2014-2099) and by Umeå School of Education (C.W-H). The authors wish to thank Tony Qwillbard for programming the data collection platform used during the intervention, Mikael Stiernstedt for support during the data collection, and Mathias Norqvist and the members of UFBI for valuable feedback and support throughout the project. 


\section{Appendix: Supplementary methods}

\section{Figure S1.}

Example of a mathematical task used during the learning intervention. a) In the AR condition, participants were presented with the task (in this case the matches task) as well as a solution template, i.e., a formula and a concrete example how to execute the formula on the specific task. b) In the CMR condition, on the other hand, participants were presented with the task, but did not receive a solution template, i.e., no information regarding the formula nor an example. Instead, on every third trial in a CMR task set participants were given a formula question, asking participants to construct an appropriate formula for the task. 
bioRxiv preprint doi: https://doi.org/10.1101/2021.03.30.437492; this version posted March 30, 2021. The copyright holder for this preprint (which was not certified by peer review) is the author/funder. All rights reserved. No reuse allowed without permission.

Training AR task, method provided

(a)

When squares are put in a row, it looks as the

picture on the right, 13 matches are needed

for four squares.

If $\mathrm{x}$ is the number of squares then the number

of matches $y$ could be calculated by the

function $y=3 x+1$

Example: If four squares are put in a row then $y$

$=3 x+1=3^{*} 4+1=13$ matches needed

How many matches are needed to get 100

squares in a row?

(b)

Training CMR task

When squares are put in a row, it looks as
the picture on the right,
13 matches are needed for four squares.
$\begin{aligned} & \text { How many matches are needed to get } 100 \\ & \text { squares in a row? }\end{aligned}$


Figure $S 2$.

Six additional examples of mathematical tasks used during the learning intervention.

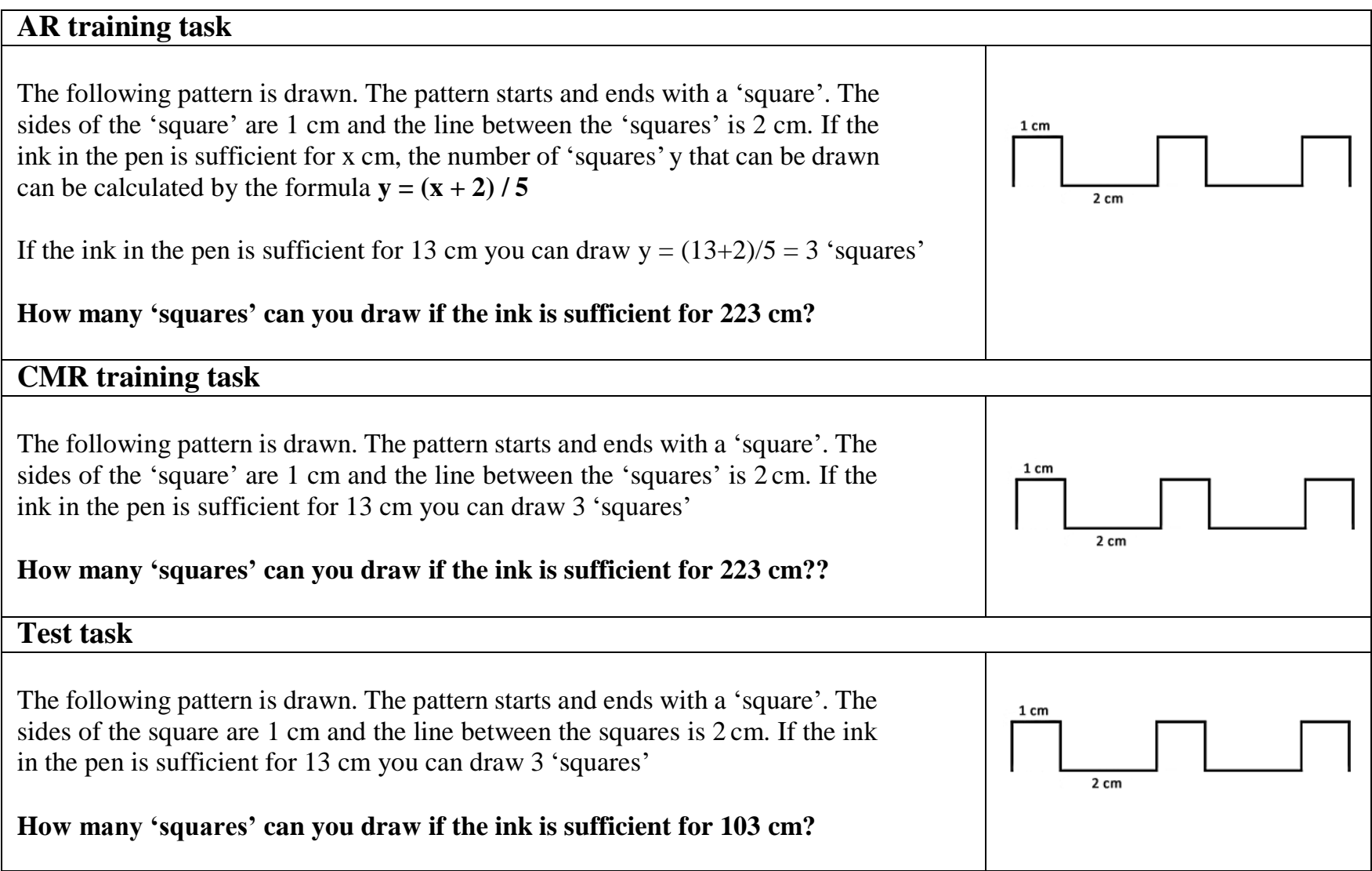

\begin{tabular}{l}
\hline AR training task \\
A tap leaks 1 drop per minute. For each drop that falls, the water surface in the test \\
tube rises $1 \mathrm{~mm}$. After 1 hour, the test tube also starts to leak, with 3 drops per minute \\
If $\mathrm{x}$ is the number of minutes after the test tube starts to leak, the height of water in the \\
test tube $\mathrm{y}$ can be calculated with the formula $\mathbf{y}=\mathbf{6 0}-\mathbf{2 x}$ \\
If the test tube leaked water for 2 minutes, the height is water in the test tube, \\
$\mathrm{y}=60-2 \cdot 2=56 \mathrm{~mm}$ \\
What is the height of water in the test tube if the tube has leaked for $\mathbf{1 2}$ minutes? \\
\hline CMR training task
\end{tabular}




\begin{abstract}
A tap leaks 1 drop per minute. For each drop that falls, the water surface in the test tube rises $1 \mathrm{~mm}$. After 1 hour, the test tube also starts to leak, with 3 drops per minute If the test tube leaked water for 2 minutes, the height is water in the test tube is 56 $\mathrm{mm}$

What is the height of water in the test tube if the tube has leaked for 12 minutes?
\end{abstract}

\title{
Test task
}

A tap leaks 1 drop per minute. For each drop that falls, the water surface in the test tube rises $1 \mathrm{~mm}$. After 1 hour, the test tube also starts to leak, with 3 drops per minute If the test tube leaked water for 2 minutes, the height is water in the test tube is 56 $\mathrm{mm}$

What is the height of water in the test tube if the tube has leaked for $\mathbf{1 0}$ minutes? 


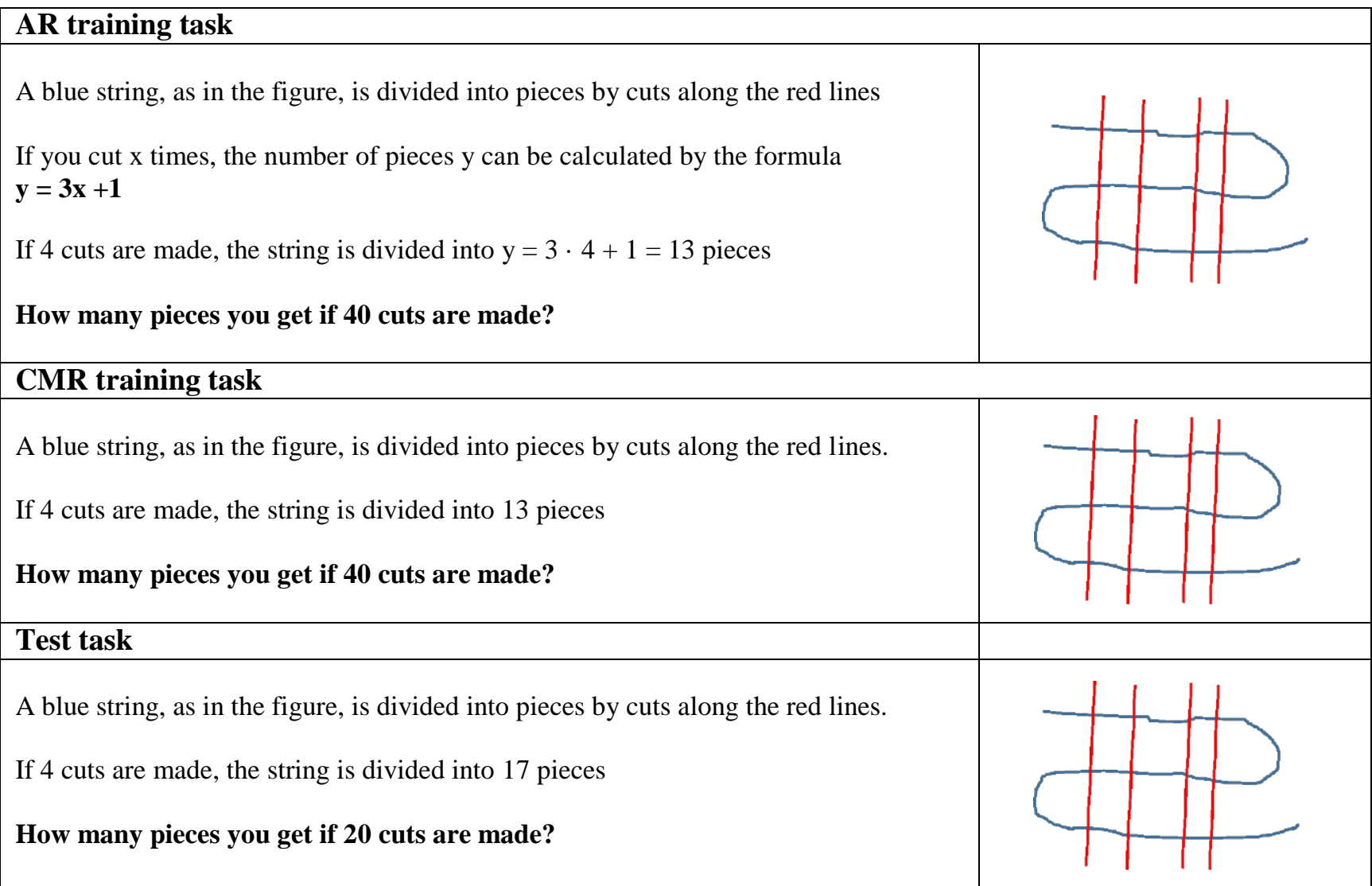

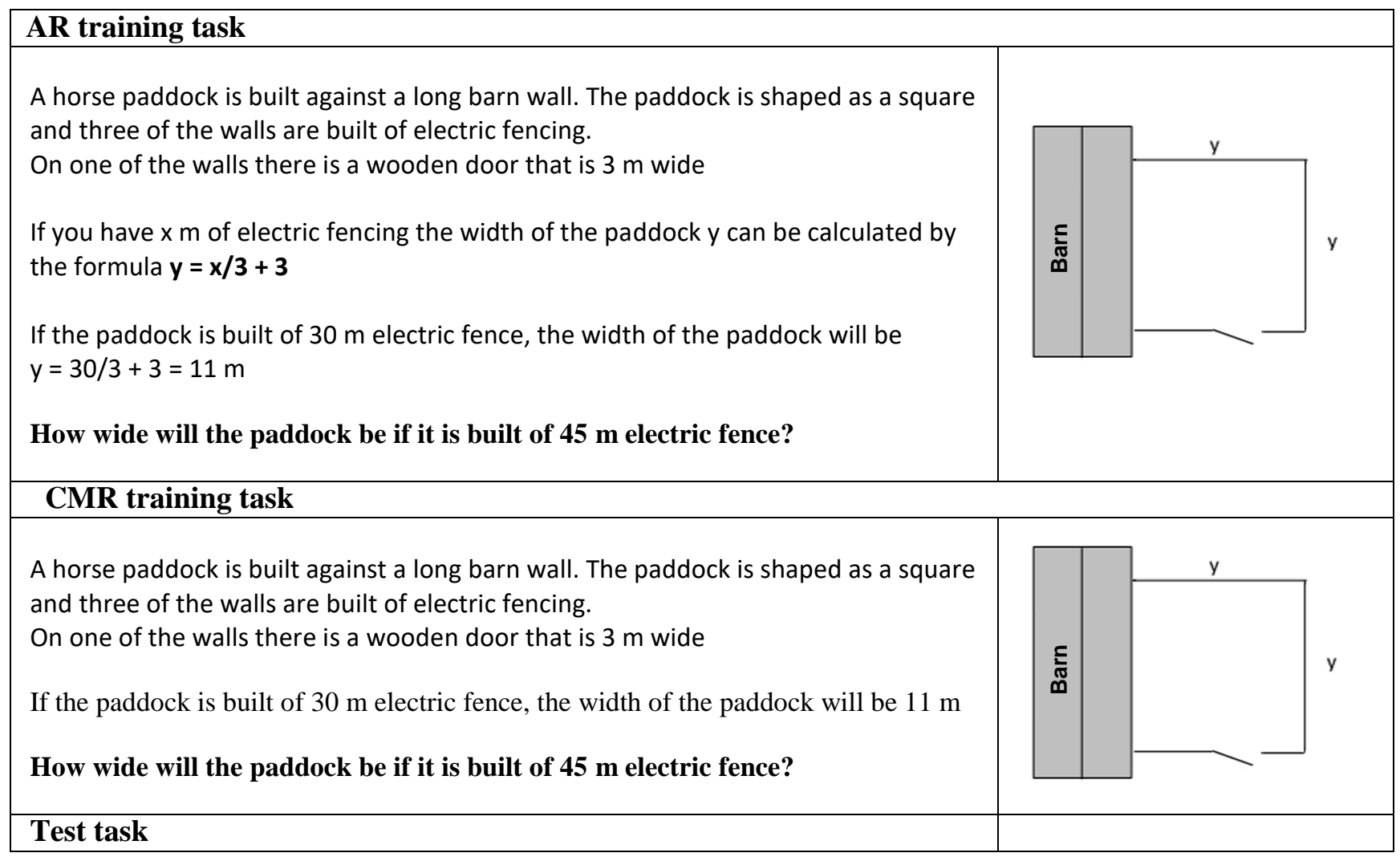


bioRxiv preprint doi: https://doi.org/10.1101/2021.03.30.437492; this version posted March 30, 2021. The copyright holder for this preprint (which was not certified by peer review) is the author/funder. All rights reserved. No reuse allowed without permission.

A horse paddock is built against a long barn wall. The paddock is shaped as a square and three of the walls are built of electric fencing.

On one of the walls there is a wooden door that is $3 \mathrm{~m}$ wide

If the paddock is built of 30 m electric fence, the width of the paddock will be $11 \mathrm{~m}$

How wide will the paddock be if it is built of $60 \mathrm{~m}$ electric fence?

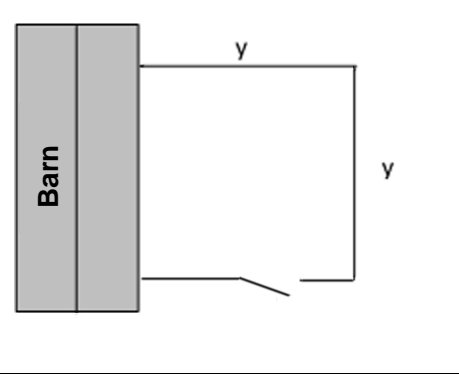




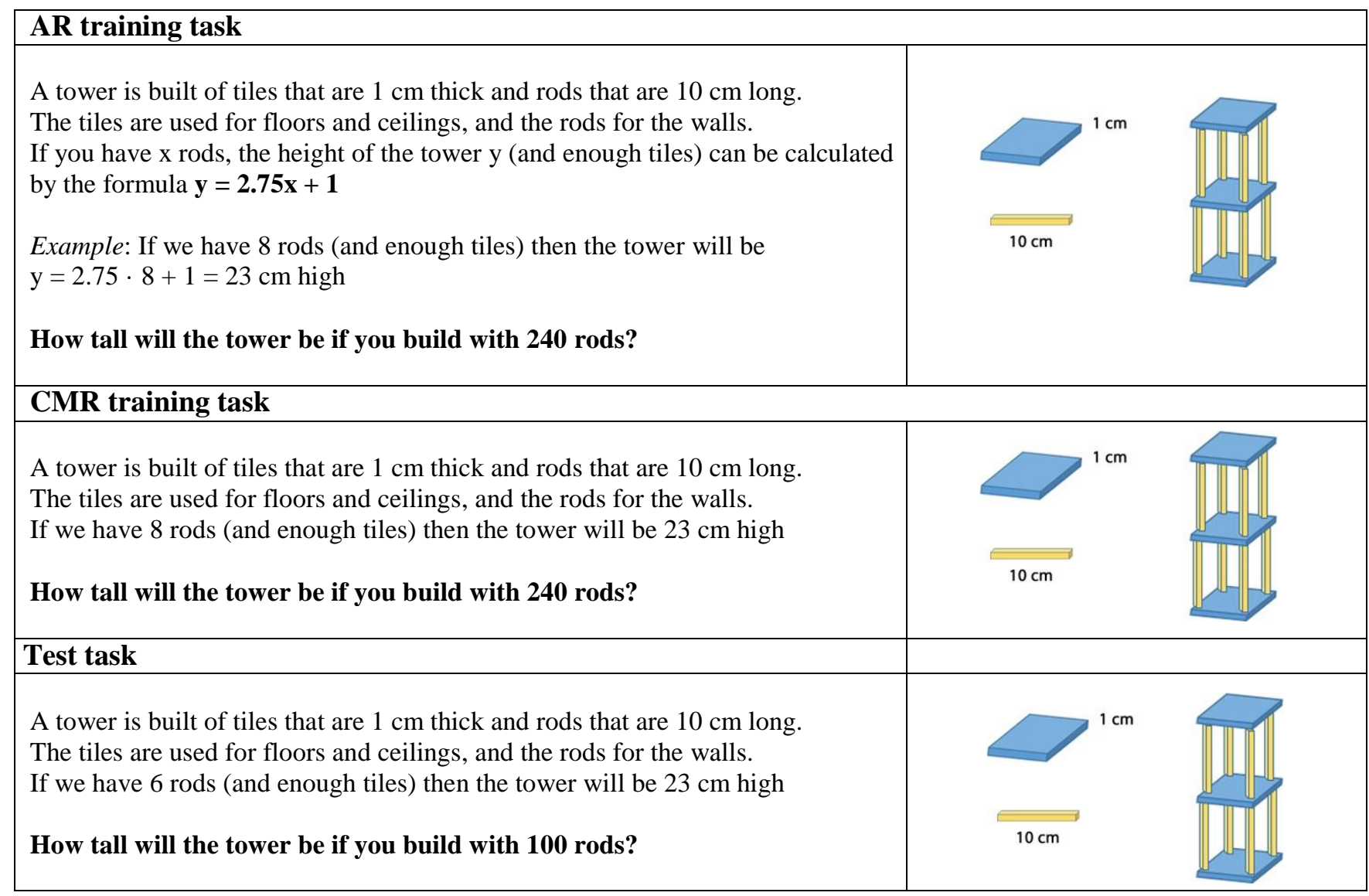

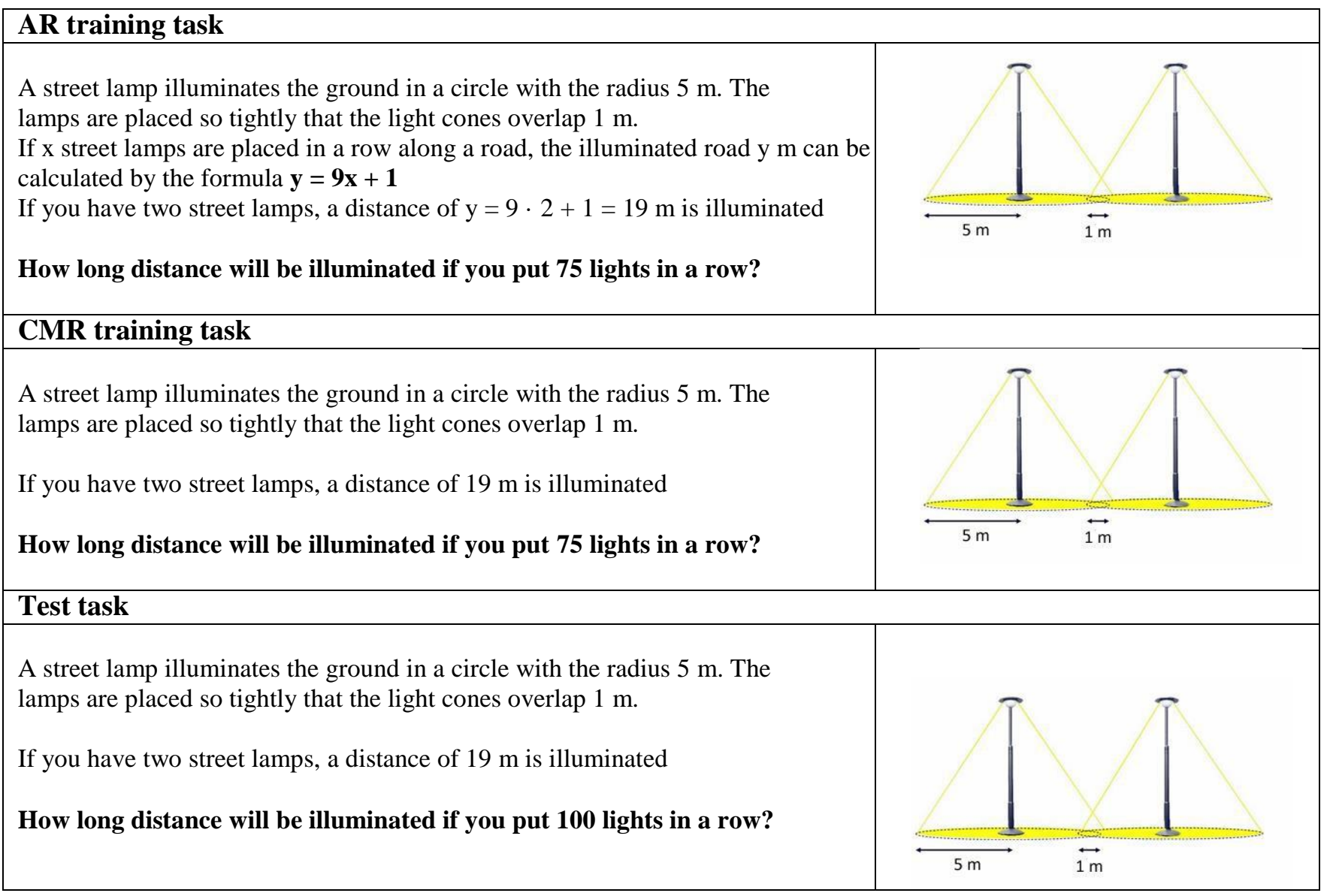




\section{References}

Alloway, T. P., \& Alloway, R. G. (2010). Investigating the predictive roles of working memory and IQ in academic attainment. J Exp Child Psychol, 106(1), 20-29. Retrieved from <Go to ISI $>$ ://WOS:000276473400002. doi:10.1016/j.jecp.2009.11.003

Amalric, M., \& Dehaene, S. (2016). Origins of the brain networks for advanced mathematics in expert mathematicians. Proc Natl Acad Sci U S A, 113(18), 4909-4917. Retrieved from <Go to ISI>://WOS:000375395700023. doi:10.1073/pnas.1603205113

Amalric, M., \& Dehaene, S. (2019). A distinct cortical network for mathematical knowledge in the human brain. Neuroimage, 189, 19-31. Retrieved from <Go to ISI>://WOS:000461166900002. doi:10.1016/j.neuroimage.2019.01.001

Arsalidou, M., Pawliw-Levac, M., Sadeghi, M., \& Pascual-Leone, J. (2018). Brain areas associated with numbers and calculations in children: Meta-analyses of fMRI studies. Developmental Cognitive Neuroscience, 30, 239-250. Retrieved from < Go to ISI>://WOS:000432146500027. doi:10.1016/j.den.2017.08.002

Arsalidou, M., \& Taylor, M. J. (2011). Is 2+2=4? Meta-analyses of brain areas needed for numbers and calculations. Neuroimage, 54(3), 2382-2393. Retrieved from http://www.ncbi.nlm.nih.gov/pubmed/20946958. doi:10.1016/j.neuroimage.2010.10.009

Binder, J. R., \& Desai, R. H. (2011). The neurobiology of semantic memory. Trends Cogn Sci, 15(11), 527-536. Retrieved from http://www.ncbi.nlm.nih.gov/pubmed/22001867. doi:10.1016/j.tics.2011.10.001 
Binder, J. R., Desai, R. H., Graves, W. W., \& Conant, L. L. (2009). Where is the semantic system? A critical review and meta-analysis of 120 functional neuroimaging studies. Cereb Cortex, 19(12), 2767-2796. Retrieved from http://www.ncbi.nlm.nih.gov/pubmed/19329570. doi:10.1093/cercor/bhp055

Bloechle, J., Huber, S., Bahnmueller, J., Rennig, J., Willmes, K., Cavdaroglu, S., . . Klein, E. (2016). Fact Learning in Complex Arithmetic-The Role of the Angular Gyrus Revisited. Hum Brain Mapp, 37(9), 3061-3079. Retrieved from < Go to ISI>://WOS:000382484600001. doi:10.1002/hbm.23226

Boesen, J., Helenius, O., Bergqvist, E., Bergqvist, T., Lithner, J., Palm, T., \& Palmberg, B. (2014). Developing mathematical competence: From the intended to the enacted curriculum. The Journal of Mathematical Behavior, 33(0), 72-87. Retrieved from http://www.sciencedirect.com/science/article/pii/S0732312313000801. doi:http://dx.doi.org/10.1016/j.jmathb.2013.10.001

Bonner, M. F., Peelle, J. E., Cook, P. A., \& Grossman, M. (2013). Heteromodal conceptual processing in the angular gyrus. Neuroimage, 71(0), 175-186. Retrieved from http://www.sciencedirect.com/science/article/pii/S1053811913000372. doi:http://dx.doi.org/10.1016/j.neuroimage.2013.01.006

Cabeza, R., Ciaramelli, E., Olson, I. R., \& Moscovitch, M. (2008). The parietal cortex and episodic memory: an attentional account. Nat Rev Neurosci, 9(8), 613-625. Retrieved from http://www.ncbi.nlm.nih.gov/pubmed/18641668. doi:10.1038/nrn2459

Ciaramelli, E., Grady, C. L., \& Moscovitch, M. (2008). Top-down and bottom-up attention to memory: a hypothesis (AtoM) on the role of the posterior parietal cortex in memory retrieval. Neuropsychologia, 46(7), 1828-1851. Retrieved from http://www.ncbi.nlm.nih.gov/pubmed/18471837. doi:10.1016/j.neuropsychologia.2008.03.022 
Dahlin, E., Neely, A. S., Larsson, A., Backman, L., \& Nyberg, L. (2008). Transfer of learning after updating training mediated by the striatum. Science, 320(5882), 1510-1512. Retrieved from http://www.ncbi.nlm.nih.gov/pubmed/18556560. doi:10.1126/science. 1155466

Dehaene, S., Piazza, M., Pinel, P., \& Cohen, L. (2003). Three parietal circuits for number processing. Cogn Neuropsychol, 20(3), 487-506. Retrieved from http://www.ncbi.nlm.nih.gov/pubmed/20957581. doi:10.1080/02643290244000239

Delazer, M., Domahs, F., Bartha, L., Brenneis, C., Lochy, A., Trieb, T., \& Benke, T. (2003). Learning complex arithmetic - an fMRI study. Cognitive Brain Research, 18(1), 7688. Retrieved from <Go to ISI>://WOS:000187633000008. doi:10.1016/j.cogbraines.2003.09.005

Donnelly, P. M., Huber, E., \& Yeatman, J. D. (2019). Intensive Summer Intervention Drives Linear Growth of Reading Skill in Struggling Readers. Front Psychol, 10, 10. Retrieved from <Go to ISI $>$ ://WOS:000482437100001. doi:10.3389/fpsyg.2019.01900

Foisy, L. M. B., Matejko, A. A., Ansari, D., \& Masson, S. Teachers as Orchestrators of Neuronal Plasticity: Effects of Teaching Practices on the Brain. Mind Brain and Education, 14. Retrieved from <Go to ISI>://WOS:000556730900001. doi:10.1111/mbe.12257

Freeman, S., Eddy, S. L., McDonough, M., Smith, M. K., Okoroafor, N., Jordt, H., \& Wenderoth, M. P. (2014). Active learning increases student performance in science, engineering, and mathematics. Proc Natl Acad Sci U S A, 111(23), 8410-8415. Retrieved from <Go to ISI>://WOS:000336976000041. doi:10.1073/pnas.1319030111

Gathercole, S. E., Pickering, S. J., Knight, C., \& Stegmann, Z. (2004). Working memory skills and educational attainment: Evidence from national curriculum assessments at 7 

and 14 years of age. Applied Cognitive Psychology, 18(1), 1-16. Retrieved from <Go to ISI>://WOS:000188508200001. doi:10.1002/acp.934

Grabner, R. H., Ansari, D., Koschutnig, K., Reishofer, G., Ebner, F., \& Neuper, C. (2009). To retrieve or to calculate? Left angular gyrus mediates the retrieval of arithmetic facts during problem solving. Neuropsychologia, 47(2), 604-608. Retrieved from http://www.ncbi.nlm.nih.gov/pubmed/19007800. doi:10.1016/j.neuropsychologia.2008.10.013

Grabner, R. H., Ansari, D., Reishofer, G., Stern, E., Ebner, F., \& Neuper, C. (2007). Individual differences in mathematical competence predict parietal brain activation during mental calculation. Neuroimage, 38(2), 346-356. Retrieved from http://www.ncbi.nlm.nih.gov/pubmed/17851092. doi:10.1016/j.neuroimage.2007.07.041

Grabner, R. H., Reishofer, G., Koschutnig, K., \& Ebner, F. (2011). Brain correlates of mathematical competence in processing mathematical representations. Front Hum Neurosci, 5, 11. Retrieved from <Go to ISI>://WOS:000297940600001. doi:10.3389/fnhum.2011.00130

Gray, O., Fry, L., \& Montaldi, D. (2020). Information content best characterises the hemispheric selectivity of the inferior parietal lobe: a meta-analysis. Scientific Reports, 10(1), 9. Retrieved from <Go to ISI>://WOS:000573754300004. doi:10.1038/s41598-020-72228-8

Gullick, M. M., Sprute, L. A., \& Temple, E. (2011). Individual differences in working memory, nonverbal IQ, and mathematics achievement and brain mechanisms associated with symbolic and nonsymbolic number processing. Learning and Individual Differences, 21(6), 644-654. Retrieved from 


\section{http://www.sciencedirect.com/science/article/pii/S1041608010001226.} doi:https://doi.org/10.1016/j.lindif.2010.10.003

Hiebert, J. (2003). What research says about the NCTM Standards. In J. Kilpatrick, G. Martin, \& D. Schifter (Eds.), A research companion to principles and standards for school mathematics (pp. 5-26). Reston, VA: National Council of TEachers of Mathematics.

Hoffman, P. (2018). An individual differences approach to semantic cognition: Divergent effects of age on representation, retrieval and selection. Scientific Reports, 8, 13. Retrieved from <Go to ISI>://WOS:000433061300027. doi:10.1038/s41598-01826569-0

Ischebeck, A., Zamarian, L., Egger, K., Schocke, M., \& Delazer, M. (2007). Imaging early practice effects in arithmetic. Neuroimage, 36(3), 993-1003. Retrieved from http://www.ncbi.nlm.nih.gov/pubmed/17490893. doi:10.1016/j.neuroimage.2007.03.051

Ischebeck, A., Zamarian, L., Siedentopf, C., Koppelstatter, F., Benke, T., Felber, S., \& Delazer, M. (2006). How specifically do we learn? Imaging the learning of multiplication and subtraction. Neuroimage, 30(4), 1365-1375. Retrieved from http://www.ncbi.nlm.nih.gov/pubmed/16413795.

doi:10.1016/j.neuroimage.2005.11.016

Jäder, J., Lithner, J., \& Sidenvall, J. Mathematical problem solving in textbooks from twelve countries. International Journal of Mathematical Education in Science and Technology, 17. Retrieved from <Go to ISI>://WOS:000484213400001. doi:10.1080/0020739x.2019.1656826

Jonsson, B., Granberg, C., \& Lithner, J. (2020a). Gaining Mathematical Understanding: The Effects of Creative Mathematical Reasoning and Cognitive Proficiency. Front 
Psychol, 11, 16. Retrieved from <Go to ISI >://WOS:000603976300001. doi:10.3389/fpsyg.2020.574366

Jonsson, B., Kulaksiz, Y. C., \& Lithner, J. (2016). Creative and algorithmic mathematical reasoning: effects of transfer-appropriate processing and effortful struggle. International Journal of Mathematical Education in Science and Technology, 47(8), 1206-1225. Retrieved from <Go to ISI >://WOS:000387791400004. doi:10.1080/0020739x.2016.1192232

Jonsson, B., Norqvist, M., Liljekvist, Y., \& Lithner, J. (2014). Learning mathematics through algorithmic and creative reasoning. The Journal of Mathematical Behavior, 36, 20-32. doi:http://dx.doi.org/10.1016/j.jmathb.2014.08.003

Jonsson, B., Wiklund-Hörnqvist, C., Stenlund, T., Andersson, M., \& Nyberg, L. (2020b). A learning method for all: The testing effect is independent of cognitive ability. Journal of Educational Psychology. doi:10.1037/edu0000627

Kim, H. (2020). An integrative model of network activity during episodic memory retrieval and a meta-analysis of fMRI studies on source memory retrieval. Brain Res, 1747, 16. Retrieved from <Go to ISI $>$ ://WOS:000572952300007. doi:10.1016/j.brainres.2020.147049

Klein, E., Willmes, K., Bieck, S. M., Bloechle, J., \& Moeller, K. (2019). White matter neuroplasticity in mental arithmetic: Changes in hippocampal connectivity following arithmetic drill training. Cortex, 114, 115-123. Retrieved from $<$ Go to ISI>://WOS:000466253700011. doi:10.1016/j.cortex.2018.05.017

Kyttälä, M., \& Lehto, J. E. (2008). Some factors underlying mathematical performance: The role of visuospatial working memory and non-verbal intelligence. European Journal of Psychology of Education, 23(1), 77. Retrieved from https://doi.org/10.1007/BF03173141. doi:10.1007/BF03173141 
Lithner, J. (2008). A research framework for creative and imitative reasoning. Educational Studies in Mathematics, 67(3), 255-276. Retrieved from http://dx.doi.org/10.1007/s10649-007-9104-2. doi:10.1007/s10649-007-9104-2

Lithner, J. (2017). Principles for designing mathematical tasks that enhance imitative and creative reasoning. Zdm-Mathematics Education, 49(6), 937-949. Retrieved from <Go to ISI>://WOS:000412893600010. doi:10.1007/s11858-017-0867-3

Lövdén, M. (2003). The episodic memory and inhibition accounts of age-related increases in false memories: A consistency check. Journal of Memory and Language, 49, 268-283. http://dx.doi.org/10.1016/S0749-596X(03)00069-X

Martin, A., \& Chao, L. L. (2001). Semantic memory and the brain: structure and processes. Curr Opin Neurobiol, 11(2), 194-201. Retrieved from < Go to ISI>://WOS:000168505500008. doi:10.1016/s0959-4388(00)00196-3

Miyake, A., Friedman, N. P., Emerson, M. J., Witzki, A. H., Howerter, A., \& Wager, T. D. (2000). The unity and diversity of executive functions and their contributions to complex "Frontal Lobe" tasks: a latent variable analysis. Cogn Psychol, 41(1), 49-100. Retrieved from http://www.ncbi.nlm.nih.gov/pubmed/10945922. doi:10.1006/cogp.1999.0734

Norqvist, M. (2018). The effect of explanations on mathematical reasoning tasks. International Journal of Mathematical Education in Science and Technology, 49(1), 15-30. Retrieved from <Go to ISI >:/WOS:000427408100003. doi:10.1080/0020739x.2017.1340679

Norqvist, M., Jonsson, B., Lithner, J., Qwillbard, T., \& Holm, L. (2019). Investigating algorithmic and creative reasoning strategies by eye tracking. Journal of Mathematical Behavior, 55, 14. Retrieved from <Go to ISI>://WOS:000484789500012. doi:10.1016/j.jmathb.2019.03.008 
Nyroos, M., Jonsson, B., Korhonen, J., \& Eklöf, H. (2015). Children's mathematical achievement and how it relates to working memory, test anxiety and self-regulation: A person-centred approach. Education Inquiry., 6(1). Retrieved from http://www.education-inquiry.net/index.php/edui/article/view/26026

\section{http://www.education-inquiry.net/index.php/edui/article/download/26026/pdf_9.} doi:10.3402/edui.v6.26026

Peters, L., \& De Smedt, B. (2018). Arithmetic in the developing brain: A review of brain imaging studies. Developmental Cognitive Neuroscience, 30, 265-279. Retrieved from <Go to ISI >://WOS:000432146500029. doi:10.1016/j.den.2017.05.002

Price, C. J. (2010). The anatomy of language: a review of 100 fMRI studies published in 2009. Ann N Y Acad Sci, 1191(1), 62-88. Retrieved from http://dx.doi.org/10.1111/j.1749-6632.2010.05444.x. doi:10.1111/j.1749$6632.2010 .05444 . \mathrm{x}$

Price, G. R., Mazzocco, M. M. M., \& Ansari, D. (2013). Why Mental Arithmetic Counts: Brain Activation during Single Digit Arithmetic Predicts High School Math Scores. The Journal of Neuroscience, 33(1), 156-163. Retrieved from https://www.jneurosci.org/content/jneuro/33/1/156.full.pdf. doi:10.1523/jneurosci.2936-12.2013

Raven, J., Raven, J. C., \& Court, J. H. (1998). Manual for Raven's Progressive Matrices and Vocabulary Scales. Section 4, The Advanced Progressive Matrices. Oxford: Oxford Psychologists Press.

Salami, A., Eriksson, J., Kompus, K., Habib, R., Kauppi, K., \& Nyberg, L. (2010). Characterizing the neural correlates of modality-specific and modality-independent accessibility and availability signals in memory using partial-least squares. Neuroimage, 52(2), 686-698. Retrieved from 
http://www.ncbi.nlm.nih.gov/pubmed/20420925. doi:10.1016/j.neuroimage.2010.04.195

201

202

Schmiedek, F., Lövdén, M., \& Lindenberger, U. (2010). Hundred days of cognitive training enhance broad cognitive abilities in adulthood: Findings from the COGITO study. Frontiers in Aging Neuroscience, 2, 27. http://dx.doi.org/10.3389/fnagi.2010.00027

Seghier, M. L. (2013). The Angular Gyrus: Multiple Functions and Multiple Subdivisions. Neuroscientist, 19(1), 43-61. Retrieved from <Go to ISI >://WOS:000312549600009. doi:10.1177/1073858412440596

Sohn, M. H., Goode, A., Koedinger, K. R., Stenger, V. A., Fissell, K., Carter, C. S., \& Anderson, J. R. (2004). Behavioral equivalence, but not neural equivalence--neural evidence of alternative strategies in mathematical thinking. Nat Neurosci, 7(11), 1193 1194. Retrieved from http://www.ncbi.nlm.nih.gov/pubmed/15475949. doi:10.1038/nn1337

Spaniol, J., Davidson, P. S., Kim, A. S., Han, H., Moscovitch, M., \& Grady, C. L. (2009). Event-related fMRI studies of episodic encoding and retrieval: meta-analyses using activation likelihood estimation. Neuropsychologia, 47(8-9), 1765-1779. Retrieved from http://www.ncbi.nlm.nih.gov/pubmed/19428409. doi:10.1016/j.neuropsychologia.2009.02.028

Stillesjö, S., Nyberg, L., \& Wirebring, L. K. (2019). Building Memory Representations for Exemplar-Based Judgment: A Role for Ventral Precuneus. Front Hum Neurosci, 13, 16. Retrieved from <Go to ISI >://WOS:000475956500001. doi:10.3389/fnhum.2019.00228

Supekar, K., Swigart, A. G., Tenison, C., Jolles, D. D., Rosenberg-Lee, M., Fuchs, L., \& Menon, V. (2013). Neural predictors of individual differences in response to math tutoring in primary-grade school children. Proc Natl Acad Sci U S A, 110(20), 8230- 
8235. Retrieved from <Go to ISI $>$ ://WOS:000319803500056. doi:10.1073/pnas.1222154110

Unsworth, N., Heitz, R., Schrock, J., \& Engle, R. (2005). An automated version of the operation span task. Behavior Research Methods, 37(3), 498-505. Retrieved from http://dx.doi.org/10.3758/BF03192720. doi:10.3758/BF03192720

Wiklund-Hörnqvist, C., Stillesjo, S., Andersson, M., Jonsson, B., \& Nyberg, L. (2021). Retrieval practice facilitates learning by strengthening processing in both the anterior and posterior hippocampus. Brain and Behavior, 11(1), 9. Retrieved from <Go to ISI>://WOS:000580983300001. doi:10.1002/brb3.1909

Wiklund-Hörnqvist, C., Jonsson, B., Korhonen, J., Eklöf, H., \& Nyroos, M. (2016). Untangling the contribution of the subcomponents of working memory to mathematical proficiency as measured by the National tests: A study among Swedish third graders. Frontiers in Psychology, 7. Retrieved from http://www.frontiersin.org/Journal/Abstract.aspx?s=346\&name=educational_psycholo gy\&ART_DOI=10.3389/fpsyg.2016.01062

\section{http://journal.frontiersin.org/article/10.3389/fpsyg.2016.01062/full}

http://journal-cdn.frontiersin.org/article/211735/files/pubmed-zip/versions/1/pdf. doi:10.3389/fpsyg.2016.01062

Wirebring, L. K., Lithner, J., Jonsson, B., Liljekvist, Y., Norqvist, M., \& Nyberg, L. (2015). Learning mathematics without a suggested solution method: Durable effects on performance and brain activity. Trends in Neuroscience and Education, 4(1-2), 6-14. Retrieved from <Go to ISI $>$ ://WOS:000363545300002. doi:10.1010/j.tine.2015.03.002

Wirebring, L. K., Wiklund-Hörnqvist, C., Eriksson, J., Andersson, M., Jonsson, B., \& Nyberg, L. (2015). Lesser Neural Pattern Similarity across Repeated Tests Is 
Associated with Better Long-Term Memory Retention. Journal of Neuroscience, 35(26), 9595-9602. Retrieved from <Go to ISI>://WOS:000358252600007. doi:10.1523/jneurosci.3550-14.2015

Zamarian, L., Ischebeck, A., \& Delazer, M. (2009). Neuroscience of learning arithmetic-evidence from brain imaging studies. Neurosci Biobehav Rev, 33(6), 909-925. Retrieved from http://www.ncbi.nlm.nih.gov/pubmed/19428500. doi:10.1016/j.neubiorev.2009.03.005 The semantic system is involved in mathematical problem solving. Neuroimage, 166, 360-370. Retrieved from <Go to ISI>://WOS:000418716800032. 


\section{Table 1} with learning condition $(A R / C M R)$ as within subject factor and cognitive ability group 264 (low/intermediate/high) as between subject factor. $A R=$ algorithmic reasoning. $C M R=$ 265 creative mathematical reasoning.

\begin{tabular}{|c|c|c|c|c|c|c|c|c|}
\hline Cluster & Local maxima & Hem & $\mathrm{BA}$ & $x$ & $y$ & $z$ & $F$-value & $\begin{array}{l}\text { Voxels } \\
\text { (k) }\end{array}$ \\
\hline \multicolumn{9}{|c|}{$C M R>A R$} \\
\hline 1 & Inferior frontal/middle frontal & $\mathrm{L}$ & $45 / 46$ & -40 & 46 & 10 & 30.44 & 288 \\
\hline 2 & Posterior/middle cingulum & & 23 & 0 & -24 & 26 & 23.55 & 64 \\
\hline 3 & Angular gyrus & $\mathrm{L}$ & 39 & -42 & -60 & 48 & 23.05 & 66 \\
\hline 4 & Middle frontal & $\mathrm{R}$ & 46 & 42 & 52 & 10 & 20.78 & 42 \\
\hline \multicolumn{9}{|c|}{$A R>C M R$} \\
\hline 1 & Supramarginal gyrus & $\mathrm{L}$ & $40 / 48$ & -66 & -34 & 26 & 24.08 & 42 \\
\hline 2 & Middle temporal & $\mathrm{L}$ & $37 / 21$ & -46 & -58 & 12 & 21.73 & 77 \\
\hline
\end{tabular}

266 Note. $\mathrm{Hem}=$ hemisphere. $\mathrm{BA}=$ Brodmann area. Peak voxel coordinates $(\mathrm{x}, \mathrm{y}, \mathrm{z})$ in MNI space

267 (SPM12). $F$-values at the peak voxel. Voxel: $p<.01$ (FDR-corrected). Cluster: $k \geq 15$. 


\section{Figure 1}

273 Experimental setup. a) Experimental procedure, b) fMRI trial design. AR = algorithmic reasoning. $C M R=$ creative mathematical reasoning. $I S I=$ interstimulus interval. $I T I=$

275 intertrial interval. For larger versions of the task examples, see Supplementary Fig. S1. For 276 additional examples, see Fig. S2.

(a) Experimental procedure

$\begin{array}{cc}\text { Day } 1 & \text { Day } 7 \\ \text { (classroom intervention) } & \text { (fMRI) }\end{array}$

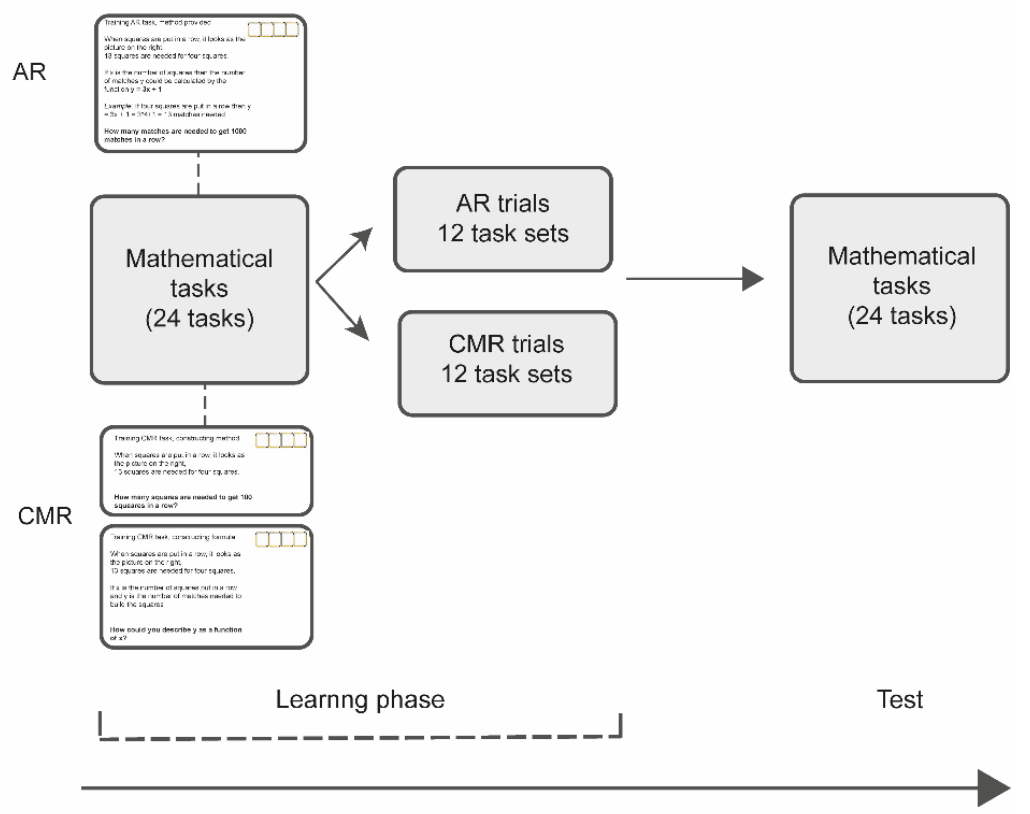

(b) fMRI trial design

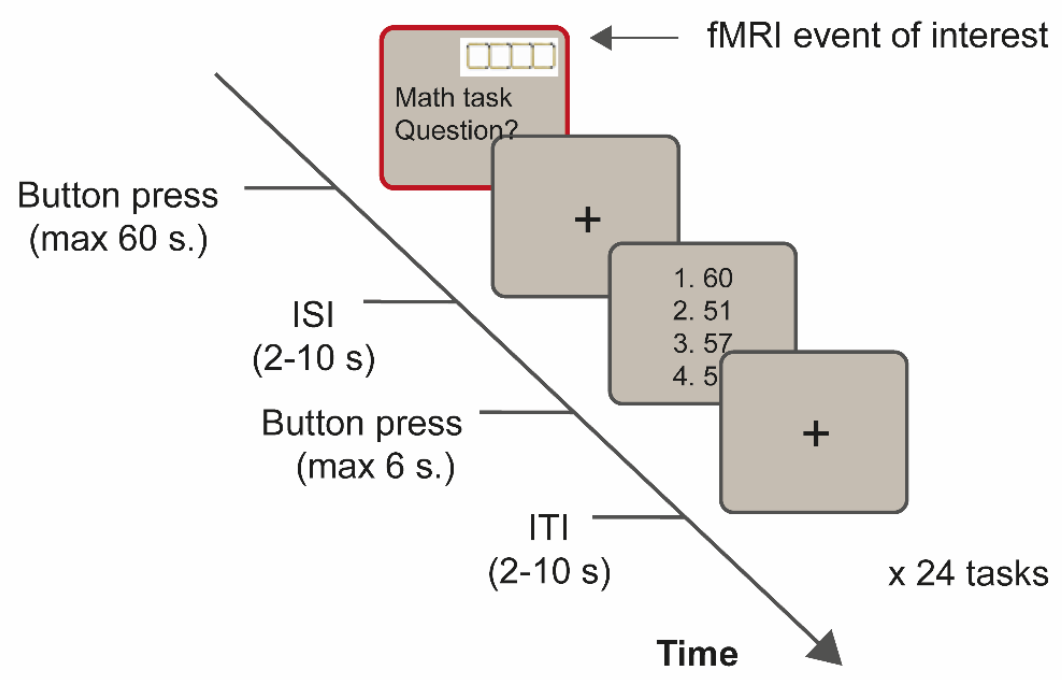




\section{Figure 2}

Behavioral performance (proportion correct) during the fMRI test. a) Mean proportion correct

(a)

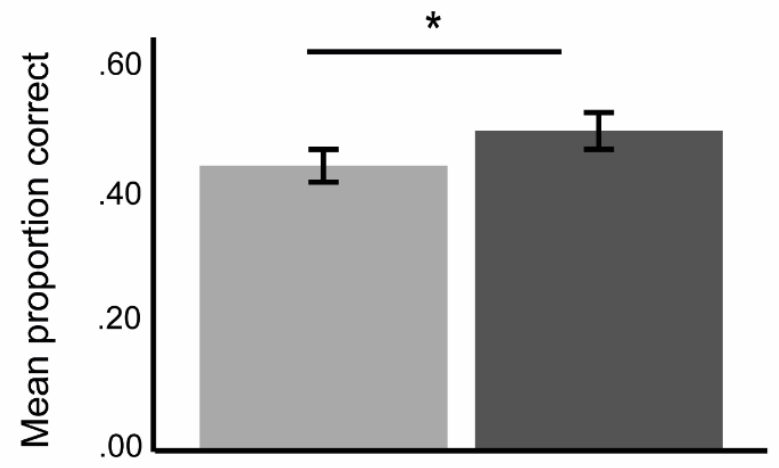

Learning condtition (b)

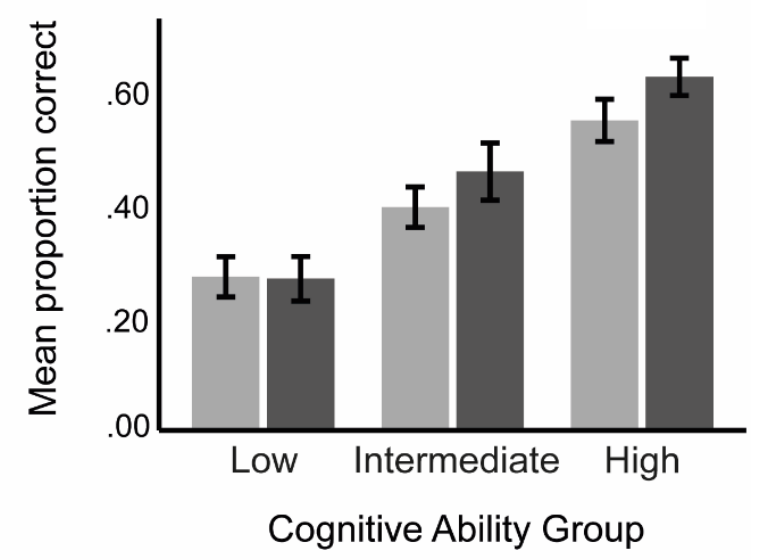

AR

CMR 
294

295

296

297 (a)

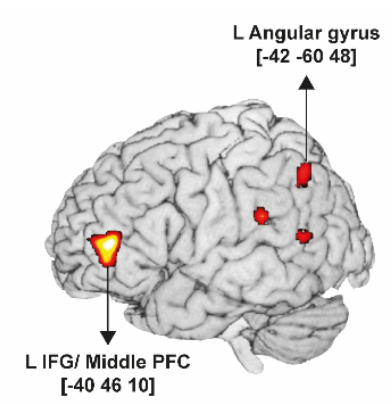

Middle PFC [42 52 10]

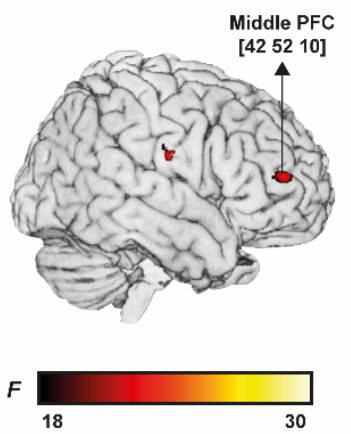

(b)

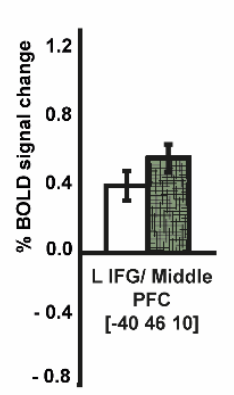

(c)
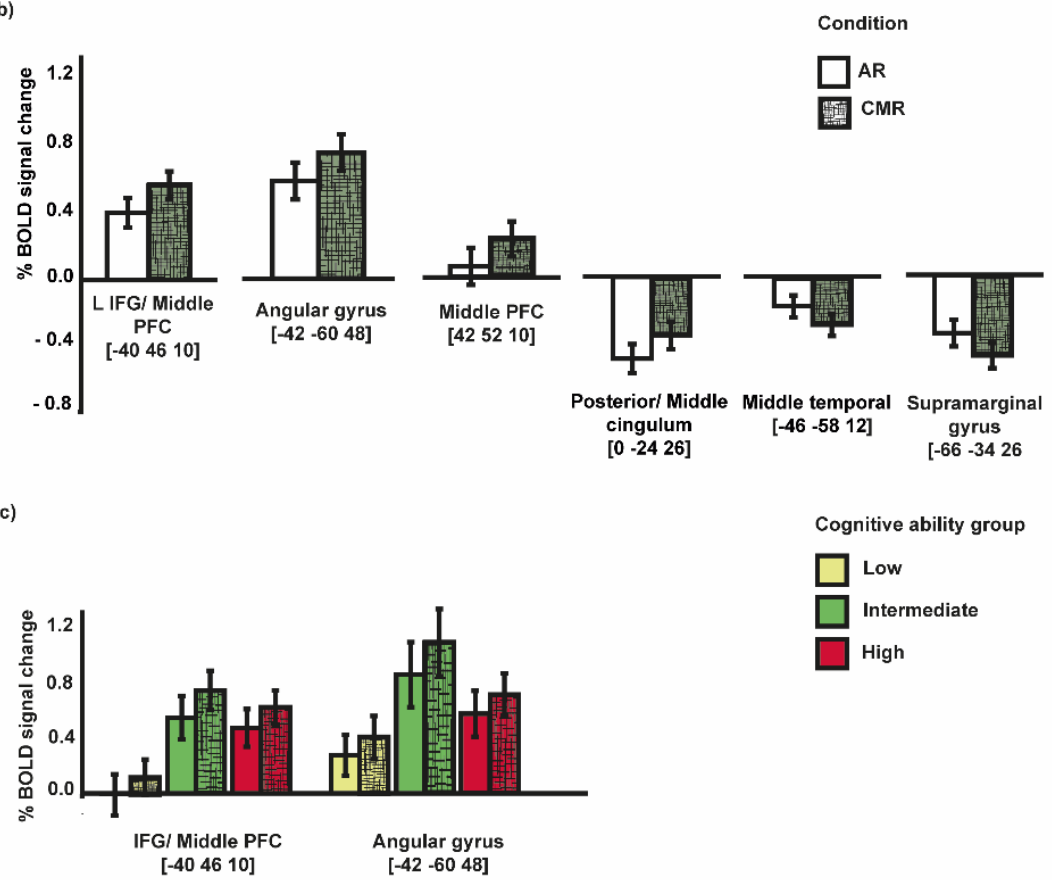

Cognitive ability group

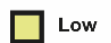

$\square$ Intermediate

High 